\title{
Infecção relacionada ao vestuário em centro cirúrgico: revisão integrativa*
}

\author{
Infection related to surgical center staff apparel: an integrative review \\ Infección relacionada con la vestimenta en centro quirúrgico: revisión integradora
}

Karina Pinheiro Teixeira ${ }^{1}$, Graciele Fernanda Costa Linch $^{2}$, Rita Catalina Aquino Caregnato ${ }^{3}$

\begin{abstract}
RESUMO: Objetivo: Analisar as evidências científicas sobre a transmissão de microrganismos relacionada ao vestuário utilizado em salas cirúrgicas. Método: Revisão integrativa de artigos publicados entre 2002 e 2012 nas bases LILACS, MEDLINE, PUBMED, SciELO e SCOPUS, em português, inglês e espanhol, utilizando-se o nível de evidência científica do Oxford Centre for Evidence Based. Resultados: A amostra foi constituída por 13 artigos, que foram classificados como se segue: seis como 2B, um como 2C e seis como 5D. Os resultados mostram que tecidos com poros demasiadamente grandes comprometem o potencial de proteção, devendo ser evitados. Recomenda-se o uso de vestimentas cirúrgicas impermeáveis, que sejam efetivas quando molhadas. Vestimentas intituladas total body exhaust foram testadas, entretanto estudos sugerem que a eficiência destas não pode ser comprovada. Conclusão: Apesar de poucos estudos testarem a capacidade de aventais reduzirem infecções, a escolha deve basear-se no tipo de cirurgia, por esta determinar o nível de proteção necessária.
\end{abstract}

PALAVRAS-CHAVE: Vestuário. Infecção. Salas cirúrgicas.

ABSTRACT: Objective: To review the scientific evidences on microorganism transmission related to the clothing used by staff in operating rooms. Method: An integrative review of articles published between 2002 and 2012 in LILACS, MEDLINE, PUBMED, SCOPUS and SciELO databases, in Portuguese, English and Spanish, using the scientific evidence level of the Oxford Center for Evidence Based. Results: The sample consisted of 13 articles that were classified as follows: six as $2 \mathrm{~B}$, one as $2 \mathrm{C}$, and six as 5D. The results show that fabrics with very large pore sizes compromise protection and, therefore, should be avoided. The use of impermeable surgical gowns, which are effective when wet, is recommended. Body-exhaust suits were tested, but studies suggest that their efficiency cannot be proven. Conclusion: Although few studies have tested the ability of aprons in reducing infection, the choice for this apparel should be based on the type of surgery, according to the level of protection required.

KEYWORDS: Clothing. Infection. Operating rooms.

RESUMEN: Objetivo: Analizar las evidencias científicas sobre la transmisión de microorganismos relacionada con la vestimenta utilizada en los quirófanos. Método: revisión integradora de los artículos publicados entre 2002-2012 en las bases LILACS, MEDLINE, PUBMED, SciELO y SCOPUS, en portugués, inglés y español, utilizando el nivel de evidencia científica del Oxford Centre for Evidence Based. Resultados: La muestra se constituyó con 13 artículos que fueron clasificados de la siguiente manera: seis como 2B, uno como 2C y seis como 5D. Los resultados muestran que las telas con poros demasiado grandes reducen el potencial de protección, y, por eso, deben evitarse. Se recomienda el uso de batas quirúrgicas impermeables que sigan siendo eficaces cuando estén húmedas. Se evaluaron las vestimentas denominadas total body exhaust, aunque su eficacia no pudo ser probada por dichos estudios. Conclusión: A pesar de los pocos estudios que evalúan la capacidad de los delantales para reducir las infecciones, la elección debe basarse en el tipo de cirugía, por ser esto lo que determina el nivel de protección necesario.

PALABRAS CLAVE: Vestimenta. Infección. Quirófanos.

\footnotetext{
'Enfermeira Graduada. Universidade Federal de Ciências da Saúde de Porto Alegre (UFCSPA). Residente de Enfermagem em Controle e Prevenção de Infecção. Hospital de Clínicas de Porto Alegre (HCPA). E-mail: karinapinheirot@gmail.com

${ }^{2}$ Doutora em Enfermagem. Professora Adjunta da Universidade Federal de Ciências da Saúde de Porto Alegre (UFCSPA). E-mail: gracielelinch@gmail.com

${ }^{3}$ Doutora em Educação. Professora Adjunta da Universidade Federal de Ciências da Saúde de Porto Alegre (UFCSPA).

Rua Doutor Rodrigues Alves, 273/203. Chácara das Pedras. CEP 91330-240. Porto Alegre, RS, Brasil.

Telefone: (51) 9942-1001. E-mail: ritac.ufcspa@gmail.com

*Artigo produzido como Trabalho de Conclusão do Curso de Enfermagem da Universidade Federal de Ciências da Saúde de Porto Alegre - UFCSPA, Porto Alegre-RS, no ${ }^{\circ}$ semestre de 2013 .
} 


\section{Introdução}

A ideia sobre transmissão de infecção existe desde os tempos remotos. Na Idade Média, existiam suspeitas que algo "sólido" poderia transmitir doenças de uma pessoa para outra, e no século XVIII, já se pensava em formas de evitar a propagação dessas doenças. A partir do momento em que as infecções e suas etiologias foram identificadas, o hospital passou a ser uma das grandes preocupações, pois neste ambiente as infecções se disseminam com maior frequência, devido a multifatores, tais como: realização de diversos procedimentos invasivos; condições clínicas fragilizadas dos pacientes, e profissionais que funcionam como transmissores ${ }^{1,2}$.

No Brasil, a preocupação com o controle das infecções hospitalares (IH) iniciou-se apenas a partir da década de 1950, apontando como causas a má esterilização de materiais, o uso indiscriminado de antibióticos e o surgimento de microrganismos resistentes ${ }^{3}$. Somente em 1983, o Ministério da Saúde (MS) publicou a primeira Portaria Ministerial $\mathrm{n}^{\mathrm{o}} 196$, referente a esta área ${ }^{4}$. Atualmente, ainda em vigor, a Portaria $n^{0}$ 2.616, de 12 de maio de 1998, define Infecção Hospitalar (IH) como "aquela adquirida após a admissão do paciente e que se manifeste durante a internação ou após a alta, quando puder ser relacionada com a internação ou procedimentos hospitalares. São também convencionadas IH aquelas manifestadas antes de 72 horas da internação, quando associadas a procedimentos diagnósticos e/ou terapêuticos, realizados durante este período"s. Atualmente, refere-se às IH como Infecções Relacionadas à Assistência à Saúde (IRAS). Entre as IRAS, as Infecções de Sítio Cirúrgico (ISC) estão entre as principais IH no Brasil, sendo que, entre as infecções encontradas em pacientes hospitalizados, $14 \%$ a $16 \%$ são ISC, ocupando, assim, a terceira posição entre todas as infecções em serviços de saúde ${ }^{6}$.

Um estudo ${ }^{7}$ identificou o Diagnóstico de Enfermagem "risco para infecção" em 100\% dos pacientes submetidos a procedimentos cirúrgicos gerais. Inúmeros fatores estão relacionados à etiologia da ISC, como o preparo préoperatório ineficiente, o procedimento cirúrgico utilizado, a habilidade técnica da equipe cirúrgica e o ambiente do Centro Cirúrgico (CC) ${ }^{8}$.

A adequada higiene das mãos é a medida preventiva mais importante na prevenção das IRAS ${ }^{9}$; entretanto, dentre os mecanismos utilizados para controle das ISC no ambiente do $\mathrm{CC}$, está o vestuário usado pela equipe durante a cirurgia. A paramentação tem como objetivo, além de evitar o contato da pele da equipe com sangue e fluidos corporais do paciente, formar uma barreira física, a fim de reduzir a dispersão de células epiteliais que, ao se desprenderem da pele, levam bactérias para o ar e, posteriormente, ao sítio cirúrgico ${ }^{10}$. Desta forma, a atenção a esta temática torna-se relevante, visto que a má utilização ou manipulação, ou até mesmo a utilização de material inadequado em relação a essas vestimentas, podem contribuir para a propagação de ISC durante os procedimentos cirúrgicos.

Apesar da existência de normas, estabelecendo regras, incluindo questões de vestimenta, como medidas de proteção à segurança e à saúde dos profissionais. ${ }^{11,12}$, pouco se tem discutido sobre o risco e os benefícios que as vestimentas dos profissionais podem trazer aos pacientes, principalmente durante procedimentos invasivos, como uma cirurgia.

Considerando-se a histórica relação encontrada entre as práticas de Enfermagem e os desfechos de infecção ${ }^{13}$, aliada à experiência de uma das autoras desta pesquisa como Bolsista de Iniciação Científica na área de Microbiologia, surgiu o interesse pelo controle de infecções e pela biossegurança, incentivando a escolha do tema como foco desta pesquisa.

Ressaltando a importância das ações de prevenção para o controle das infecções, compreende-se que é papel do profissional de Enfermagem intensificar suas práticas diárias de prevenção, produzindo e reproduzindo conhecimento preventivo ${ }^{14,15}$. Diante deste contexto apresentado e da inserção do profissional de Enfermagem no controle das infecções, na biossegurança e na educação, entende-se que a pesquisa sobre o tema poderá contribuir para a qualificação dos profissionais da saúde, reforçando práticas seguras no ambiente hospitalar.

\section{Objetivo}

Analisar as evidências científicas sobre a transmissão de microrganismos relacionados ao vestuário utilizado por profissionais em salas cirúrgicas.

\section{Método}

Trata-se de uma Revisão Integrativa (RI), método de pesquisa que consiste em agrupar os resultados obtidos de pesquisas primárias em uma análise ampla da literatura disponível sobre um determinado tema, com o objetivo de desenvolver uma explicação mais abrangente de um fenômeno específico ${ }^{16-19}$.

Este estudo foi desenvolvido em cinco etapas: formulação do problema; coleta de dados; avaliação dos dados; análise e interpretação dos dados coletados, e apresentação dos resultados ${ }^{16}$. Diante do objetivo desta RI, a formulação do problema traçado foi: 'Qual a relação entre o vestuário utilizado em salas de cirurgias e a transmissão das infecções?'.

As bases de dados eletrônicas utilizadas foram: Literatura Latino-Americana e do Caribe em Ciências de Saúde (LILACS), Medical Literature Analysis and Retrieval System Online (MEDLINE), US National Library of Medicine National Institutes of Health (PUBMED), Scientific Electronic Library Online (SciELO) e SCOPUS. O período de coleta dos dados ocorreu nos meses de fevereiro e março de 2013, utilizando-se os descritores controlados obtidos nos Descritores em Ciências da Saúde (DeCS) em português, inglês e espanhol, respectivamente: vestuário, infecção, 
salas de cirurgia; clothing, infection, operating rooms; ropa, infección, quirófanos.

A coleta de dados foi realizada através da leitura dos títulos e resumos, a fim de identificar os artigos que atendiam aos seguintes critérios de inclusão: ter sido publicado entre 2002 e 2012; artigos originais em língua portuguesa, inglesa e espanhola, com abordagem do vestuário utilizado em salas de cirurgias, independentemente de se tratar de paramentação ou uniforme de uso exclusivo do $\mathrm{CC}$, e livre acesso on-line. Critérios de exclusão: não abordarem a questão de pesquisa e publicações classificadas como editorial, carta ou similares.

Inicialmente, dos artigos identificados, foram excluídos 591, por não preencherem um ou mais critérios de inclusão, ou já estarem apresentados em outra base de dados. A partir da leitura dos resumos, eliminaram-se 40 artigos, por apresentarem um ou mais critérios de exclusão; e, na leitura da íntegra do artigo, eliminaram-se mais quatro artigos, visto que não abordavam diretamente o tema em questão. Desta forma, a amostra final constituiu-se de 13 artigos.

Após leitura na íntegra dos artigos da amostra, as publicações foram avaliadas e classificadas quanto ao seu rigor e às características de cada estudo, possibilitando uma classificação por nível de evidência e graus de recomendação, conforme validade e confiabilidade ${ }^{18,19}$. Nesta etapa, foi utilizado um quadro baseado na tabela de classificação de Níveis de Evidência Científica do Oxford Centre for Evidence Based Medicine ${ }^{20}$ (Quadro 1).

As informações obtidas a partir dos artigos foram analisadas, interpretadas, apresentadas e discutidas, permitindo uma descrição das características pertinentes do conteúdo em questão.

Em relação aos aspectos éticos, foram respeitados os direitos autorais dos artigos analisados.

\section{Resultados}

A Tabela 1 apresenta a síntese das buscas realizadas nas diferentes bases de dados com o mesmo conjunto de palavraschave, conforme descrição metodológica.

A amostra final constituída de 13 artigos, apresentada no quadro a seguir (Quadro 2), se caracteriza por maior predomínio de estudos publicados no período de 2002 a 2006 (7), seguindo-se 2008 (1), 2009 (1), 2011 (1) e 2012 (3). Quanto à origem dos periódicos, apenas um é nacional e os demais são estrangeiros: Reino Unido (6), Estados Unidos (5), Polônia (1). Em relação à formação dos autores, chama a atenção que apenas dois dos artigos citaram a participação de profissional Enfermeiro.

Em relação ao conteúdo, 12 artigos trazem comparações entre diferentes tipos de vestimentas usadas como paramentação cirúrgica, salientando diferentes tecidos e apresentações, relacionando-os ao seu potencial de proteção contra ISC. Observou-se que um artigo abordou estudo realizado com uniformes (não paramentação) de uso exclusivo do CC.

Do desenho dos estudos encontrados, sete publicações apresentam caráter experimental (pesquisa de campo) e seis publicações são revisões da literatura.

Sobre o cenário, quatro estudos experimentais ${ }^{21-24} \mathrm{e} u m a$ revisão da literatura ${ }^{25}$, totalizando aproximadamente $38 \%$ da amostra, basearam seus resultados em experimentos realizados durante cirurgias ortopédicas, principalmente envolvendo implante de próteses.

\section{Discussão}

As vestimentas usadas pelos profissionais durante os procedimentos cirúrgicos podem funcionar para prevenir ISC, evitando a transferência direta de microrganismos presentes na pele da equipe cirúrgica para o sítio cirúrgico, o campo ou os instrumentos, e minimizando a transferência indireta, na qual as bactérias são dispersas da pele da equipe para o ar, podendo fixar-se na área da ferida ${ }^{10,26}$.

Apesar de as vestimentas terem o objetivo de proteção, um estudo apresenta que as vestimentas cirúrgicas atraem facilmente a maioria das bactérias, independentemente da cepa, provavelmente devido à aspereza deste material, visto que a superfície rugosa proporciona uma maior área e as depressões na superfície fornecem locais mais favoráveis para colonização $0^{27}$. Outro estudo ${ }^{28}$, que quantificou e qualificou bactérias presentes em vestimentas cirúrgicas, dentre as amostras de vestimentas reutilizáveis ainda sujas, 79\% foram

Tabela 1. Descrição da seleção dos manuscritos por base de dados. Porto Alegre-RS, 2013.

\begin{tabular}{|c|c|c|c|c|c|}
\hline \multirow{2}{*}{ Base de Dados } & \multicolumn{2}{|c|}{ Busca inicial } & \multirow{2}{*}{$\begin{array}{c}\text { Leitura dos Resumos } \\
\mathrm{E}^{*}\end{array}$} & \multirow{2}{*}{$\begin{array}{c}\text { Artigo na Íntegra } \\
E^{*} \\
\end{array}$} & \multirow{2}{*}{$\begin{array}{r}\text { Fina } \\
\mathrm{S}^{*} \\
\end{array}$} \\
\hline & $\mathrm{I}^{*}$ & $\mathrm{E}^{*}$ & & & \\
\hline PUBMED & 217 & 207 & 6 & 0 & 4 \\
\hline MEDLINE & 323 & 314 & 7 & 0 & 2 \\
\hline SCOPUS & 106 & 68 & 27 & 4 & 7 \\
\hline SCIELO & 1 & 1 & 0 & 0 & 0 \\
\hline LILACS & 1 & 1 & 0 & 0 & 0 \\
\hline TOTAL & 648 & 591 & 40 & 4 & 13 \\
\hline
\end{tabular}

*I - Identificados; E - Eliminados; S - Selecionados. 
Quadro 1. Classificação de Nível de Evidência Científica baseada na tabela de classificação de Níveis de Evidência Científica do Oxford Centre for Evidence Based Medicine.

\begin{tabular}{|c|c|c|c|c|c|}
\hline $\begin{array}{c}\text { Grau de } \\
\text { recomendação }\end{array}$ & $\begin{array}{l}\text { Nível de } \\
\text { evidência }\end{array}$ & $\begin{array}{c}\text { Tratamento - Prevenção } \\
\text { - Etiologia }\end{array}$ & Prognóstico & Diagnóstico & $\begin{array}{l}\text { Diagnóstico Diferencial/ } \\
\text { Prevalência de Sintomas }\end{array}$ \\
\hline \multirow{3}{*}{ A } & $1 \mathrm{~A}$ & $\begin{array}{l}\text { Revisão sistemática } \\
\text { de ensaios clínicos } \\
\text { controlados } \\
\text { randomizados. }\end{array}$ & $\begin{array}{l}\text { Revisão Sistemática de } \\
\text { Coortes desde o início } \\
\text { da doença. Critério } \\
\text { Prognóstico validado em } \\
\text { diversas populações. }\end{array}$ & $\begin{array}{l}\text { Revisão Sistemática de } \\
\text { estudos diagnósticos nível } \\
\text { 1. Diagnóstico de estudos } \\
\text { nível 1B, em diferentes } \\
\text { centros clínicos. }\end{array}$ & $\begin{array}{l}\text { Revisão sistemática } \\
\text { de estudos de coorte } \\
\text { (contemporânea ou } \\
\text { prospectiva). }\end{array}$ \\
\hline & $1 \mathrm{~B}$ & $\begin{array}{l}\text { Ensaio clínico controlado } \\
\text { randomizado com } \\
\text { intervalo de confiança } \\
\text { estreito. }\end{array}$ & $\begin{array}{l}\text { Coorte desde o início da } \\
\text { doença, com perda }<20 \% \text {. } \\
\text { Critério prognóstico } \\
\text { validado em uma única } \\
\text { população. }\end{array}$ & $\begin{array}{l}\text { Coorte validada, com } \\
\text { bom padrão de referência. } \\
\text { Critério Diagnóstico } \\
\text { testado em um único } \\
\text { centro clínico. }\end{array}$ & $\begin{array}{l}\text { Estudo de coorte com } \\
\text { poucas perdas. }\end{array}$ \\
\hline & $1 \mathrm{C}$ & $\begin{array}{l}\text { Resultados terapêuticos } \\
\text { do tipo "tudo ou nada" }\end{array}$ & $\begin{array}{l}\text { Série de casos do tipo } \\
\text { "tudo ou nada". }\end{array}$ & $\begin{array}{l}\text { Sensibilidade e } \\
\text { especificidade próximas } \\
\text { de } 100 \% \text {. }\end{array}$ & $\begin{array}{l}\text { Série de casos do tipo } \\
\text { "tudo ou nada". }\end{array}$ \\
\hline \multirow{5}{*}{ B } & $2 \mathrm{~A}$ & $\begin{array}{l}\text { Revisão Sistemática de } \\
\text { Estudos de Coorte. }\end{array}$ & $\begin{array}{l}\text { Revisão Sistemática } \\
\text { de coortes históricas } \\
\text { (retrospectivas) ou de } \\
\text { seguimento de casos } \\
\text { não tratados de grupo } \\
\text { controle de ensaio clínico } \\
\text { randomizado. }\end{array}$ & $\begin{array}{l}\text { Revisão Sistemática de } \\
\text { estudos diagnósticos de } \\
\text { nível }>2 \text {. }\end{array}$ & $\begin{array}{l}\text { Revisão Sistemática de } \\
\text { estudos sobre diagnóstico } \\
\text { diferencial de nível }>2 \text {. }\end{array}$ \\
\hline & $2 \mathrm{~B}$ & $\begin{array}{l}\text { Estudo de Coorte } \\
\text { (incluindo Ensaio Clínico } \\
\text { Randomizado de menor } \\
\text { qualidade). }\end{array}$ & $\begin{array}{l}\text { Estudo de Coorte } \\
\text { Histórica, seguimentos } \\
\text { de pacientes não tratados } \\
\text { de grupo de controle } \\
\text { de ensaio clínico } \\
\text { randomizado. Critério } \\
\text { Prognóstico derivado } \\
\text { ou validado somente de } \\
\text { amostras fragmentadas. }\end{array}$ & $\begin{array}{l}\text { Coorte exploratória com } \\
\text { bom padrão de referência. } \\
\text { Critério Diagnóstico } \\
\text { derivado ou validado em } \\
\text { amostras fragmentadas ou } \\
\text { banco de dados. }\end{array}$ & $\begin{array}{l}\text { Estudo de coorte histórica } \\
\text { ou com seguimento de } \\
\text { casos comprometido } \\
\text { (número grande de } \\
\text { perdas). }\end{array}$ \\
\hline & $2 \mathrm{C}$ & $\begin{array}{l}\text { Observação de resultados } \\
\text { terapêuticos (outcomes } \\
\text { Research). Estudo } \\
\text { Ecológico. }\end{array}$ & $\begin{array}{l}\text { Observação de Evoluções } \\
\text { Clínicas (outcomes } \\
\text { research). }\end{array}$ & -------- & Estudo Ecológico. \\
\hline & $3 \mathrm{~A}$ & $\begin{array}{l}\text { Revisão Sistemática de } \\
\text { Estudos Caso-Controle. }\end{array}$ & ---------- & $\begin{array}{l}\text { Revisão Sistemática de } \\
\text { estudos diagnósticos de } \\
\text { nível >3B. }\end{array}$ & $\begin{array}{l}\text { Revisão Sistemática de } \\
\text { estudos de nível >3B. }\end{array}$ \\
\hline & $3 \mathrm{~B}$ & Estudo Caso-Controle. & ----------- & $\begin{array}{l}\text { Seleção não consecutiva } \\
\text { de casos ou padrão de } \\
\text { referência aplicado de } \\
\text { forma pouco consistente. }\end{array}$ & $\begin{array}{l}\text { Coorte com seleção não } \\
\text { consecutiva de casos, } \\
\text { ou população de estudo } \\
\text { muito limitada. }\end{array}$ \\
\hline $\mathrm{C}$ & 4 & $\begin{array}{l}\text { Relato de Casos } \\
\text { (incluindo coorte ou } \\
\text { caso-controle de menor } \\
\text { qualidade). }\end{array}$ & $\begin{array}{l}\text { Série de casos (e coorte } \\
\text { prognóstica de menor } \\
\text { qualidade). }\end{array}$ & $\begin{array}{l}\text { Estudo de caso- } \\
\text { controle ou padrão de } \\
\text { referência pobre ou não } \\
\text { independente. }\end{array}$ & $\begin{array}{l}\text { Série de casos, ou padrão } \\
\text { de referência superado. }\end{array}$ \\
\hline $\mathrm{D}$ & 5 & $\begin{array}{l}\text { Opinião de especialistas d } \\
\text { estudo com animais). }\end{array}$ & rovida de avaliação crític & u baseada em matérias bá & icas (estudo fisiológico ou \\
\hline
\end{tabular}

positivas para algum tipo de cocos gram-positivos, como Staphylococcus aureus e bactérias coliformes. Tais achados apontam para a necessidade de analisar atentamente o real potencial de proteção oferecido pelas vestimentas utilizadas em CC e sua possível contribuição para a contaminação dos sítios cirúrgicos.

A pele da equipe cirúrgica, durante o procedimento, é a principal fonte de dispersão de bactérias no $\operatorname{ar}^{10,29}$ e uma alta quantidade de bactérias no ar pode ser associada a um maior risco de desenvolvimento de ISC. Quatro estudos analisados discutem a relação entre a eficácia de diferentes tecidos no processo de minimizar a transferência indireta e o quantitativo de bactérias presentes no ar próximo ao campo ou à ferida cirúrgica ${ }^{10,23,26,30}$.

Comparando-se diferentes tipos de tecidos, utilizados para as vestimentas de paramentação cirúrgica, as vestimentas de 
Quadro 2. Síntese dos artigos avaliados, apresentando as variáveis: Base de dados, título, objetivos, caracterização do estudo, resultados e nível de evidência.

\begin{tabular}{|c|c|c|c|c|c|}
\hline $\begin{array}{l}\text { Base de } \\
\text { Dados }\end{array}$ & Título & Objetivos & $\begin{array}{c}\text { Caracterização do } \\
\text { Estudo }\end{array}$ & Resultados & Nível de Evidência \\
\hline $\begin{array}{l}\text { PUBMED } \\
\text { SCIELO } \\
\text { MEDLINE }\end{array}$ & $\begin{array}{l}\text { O preparo da equipe } \\
\text { cirúrgica: aspecto } \\
\text { relevante no controle } \\
\text { da contaminação } \\
\text { ambiental }^{10} \text {. }\end{array}$ & $\begin{array}{l}\text { Apresentar as atuais } \\
\text { recomendações } \\
\text { relacionadas ao preparo } \\
\text { da equipe cirúrgica } \\
\text { e discutir o papel do } \\
\text { Enfermeiro no controle } \\
\text { da contaminação } \\
\text { ambiental. }\end{array}$ & $\begin{array}{l}\text { Tipologia: Revisão } \\
\text { da literatura. Local: } \\
\text { Brasil. Amostra: Não } \\
\text { informada. }\end{array}$ & $\begin{array}{l}\text { A utilização do avental } \\
\text { objetiva reduzir a } \\
\text { dispersão das bactérias } \\
\text { no ar e evitar o contato } \\
\text { da pele da equipe } \\
\text { com sangue e fluidos } \\
\text { corporais. O CDC } \\
\text { recomenda troca de } \\
\text { avental quando estiver } \\
\text { visivelmente sujo com } \\
\text { fluído corporal. }\end{array}$ & $\begin{array}{l}\text { Nivel } 5 \text { Grau de } \\
\text { recomendação "D" }\end{array}$ \\
\hline SCOPUS & $\begin{array}{l}\text { Direct measurement of } \\
\text { bacterial penetration } \\
\text { through surgical } \\
\text { gowns: a new } \\
\text { method }^{21} \text {. }\end{array}$ & $\begin{array}{l}\text { Comparar dois tipos de } \\
\text { tecidos diferentes em } \\
\text { relação ao potencial de } \\
\text { penetração. }\end{array}$ & $\begin{array}{l}\text { Tipologia: Estudo } \\
\text { experimental. } \\
\text { Local: Reino } \\
\text { Unido. Amostra: } 40 \\
\text { vestimentas. }\end{array}$ & $\begin{array}{l}\text { Vestimentas reutilizáveis } \\
\text { demonstraram variação } \\
\text { na penetração e, por } \\
\text { esta razão, podem } \\
\text { ser inadequadas para } \\
\text { utilização. }\end{array}$ & $\begin{array}{l}\text { Nivel 2B Grau de } \\
\text { recomendação "B" }\end{array}$ \\
\hline $\begin{array}{c}\text { SCOPUS } \\
\text { PUBMED } \\
\text { MEDLINE }\end{array}$ & $\begin{array}{l}\text { Lack of influence of } \\
\text { body exhaust gowns } \\
\text { on aerobic bacterial } \\
\text { surface counts in a } \\
\text { mixed-ventilation } \\
\text { operating theatre. } \\
\text { A study of } 62 \text { hip } \\
\text { arthroplasties } \\
22 .\end{array}$ & $\begin{array}{l}\text { Avaliar o efeito } \\
\text { na sedimentação } \\
\text { bacteriana aeróbica na } \\
\text { ventilação de sala de } \\
\text { operação e comparar } \\
\text { a contaminação do ar } \\
\text { na sala do CC quando } \\
\text { utilizadas diferentes } \\
\text { paramentações. }\end{array}$ & $\begin{array}{l}\text { Tipologia: Analítico } \\
\text { (comparativo). Local: } \\
\text { Suíça. Amostra: } 62 \\
\text { artroplastias. }\end{array}$ & $\begin{array}{l}\text { Em comparação } \\
\text { com paramentação } \\
\text { convencional, o uso } \\
\text { de “body exhaust" } \\
\text { (vestimenta/ } \\
\text { paramentação que } \\
\text { inclui uma espécie de } \\
\text { capacete com sistema } \\
\text { próprio de exaustão) não } \\
\text { apresentou resultados } \\
\text { significativos na redução } \\
\text { da contaminação } \\
\text { microbiana do ar. }\end{array}$ & $\begin{array}{l}\text { Nivel 2B Grau de } \\
\text { recomendação "B" }\end{array}$ \\
\hline $\begin{array}{c}\text { PUBMED } \\
\text { MEDLINE } \\
\text { SCOPUS }\end{array}$ & $\begin{array}{l}\text { Body-exhaust suit } \\
\text { versus occlusive } \\
\text { clothing. A randomised } \\
\text { prospective trial using } \\
\text { air and wound bacterial } \\
\text { counts }^{23} \text {. }\end{array}$ & $\begin{array}{l}\text { Determinar se havia } \\
\text { uma correlação entre a } \\
\text { quantidade de bactérias } \\
\text { presente no ar e a } \\
\text { quantidade de bactérias } \\
\text { encontrada nas incisões } \\
\text { cirúrgicas realizadas } \\
\text { em ambiente com fluxo } \\
\text { de ar ultrapuro, e se } \\
\text { vestimentas oclusivas } \\
\text { "BESs" foram melhores } \\
\text { do que vestimentas } \\
\text { oclusivas "Rotecno" } \\
\text { para o controle da } \\
\text { contaminação do } \\
\text { ar próximo à ferida } \\
\text { operatória em um CC. }\end{array}$ & $\begin{array}{l}\text { Tipologia: } \\
\text { prospectivo } \\
\text { randomizado. } \\
\text { Local: Reino } \\
\text { Unido. Amostra: } 50 \\
\text { ortoplastias. }\end{array}$ & $\begin{array}{l}\text { A vestimenta oclusiva } \\
\text { hidrofóbica à base de } \\
\text { material não tecido } \\
\text { hidrotrançado (Rotecno) } \\
\text { é menos eficaz do que } \\
\text { sistema de exaustão } \\
\text { (BES). Contudo, as } \\
\text { feridas operatórias } \\
\text { eram igualmente } \\
\text { contaminadas com } \\
\text { ambos os tipos de } \\
\text { roupas, sugerindo que, } \\
\text { em níveis muito baixos } \\
\text { de contaminação do ar, a } \\
\text { contaminação da ferida a } \\
\text { partir do ar é irrelevante. }\end{array}$ & $\begin{array}{l}\text { Nivel 2B Grau de } \\
\text { recomendação "B" }\end{array}$ \\
\hline $\begin{array}{c}\text { PUBMED } \\
\text { SCOPUS } \\
\text { MEDLINE }\end{array}$ & $\begin{array}{l}\text { Comparison of three } \\
\text { distinct surgical } \\
\text { clothing systems } \\
\text { for protection from } \\
\text { air-borne bacteria: } \\
\text { A prospective } \\
\text { observational study }{ }^{24} \text {. }\end{array}$ & $\begin{array}{l}\text { Comparar a capacidade } \\
\text { de proteção entre três } \\
\text { sistemas de roupas feitas } \\
\text { de materiais diferentes: } \\
\text { uma feita de mistura } \\
\text { de algodão/poliéster e } \\
\text { duas roupas à base de } \\
\text { poliéster. }\end{array}$ & $\begin{array}{l}\text { Tipologia: Estudo } \\
\text { randomizado. } \\
\text { Local: Reino } \\
\text { Unido. Amostra: } 21 \\
\text { procedimentos. }\end{array}$ & $\begin{array}{l}\text { Ambos os tipos de } \\
\text { roupas feitas de } \\
\text { poliéster reduziu a } \\
\text { quantidade de UFC } / \mathrm{m}^{3} \\
\text { significativamente em } \\
\text { comparação com a roupa } \\
\text { feita a partir de material } \\
\text { misturado. }\end{array}$ & $\begin{array}{l}\text { Nivel 2B Grau de } \\
\text { recomendação "B" }\end{array}$ \\
\hline
\end{tabular}


Quadro 2. Continuação..

\begin{tabular}{|c|c|c|c|c|c|}
\hline $\begin{array}{l}\text { Base de } \\
\text { Dados }\end{array}$ & Título & Objetivos & $\begin{array}{c}\text { Caracterização do } \\
\text { Estudo }\end{array}$ & Resultados & Nível de Evidência \\
\hline SCOPUS & $\begin{array}{l}\text { The prevention of } \\
\text { infection in total hip } \\
\text { arthroplasty }^{25} \text {. }\end{array}$ & $\begin{array}{l}\text { Revisão baseada em } \\
\text { evidências de técnicas } \\
\text { utilizadas para reduzir } \\
\text { o risco de infecção } \\
\text { durante a artroplastia. } \\
\text { Métodos antigos e } \\
\text { contemporâneos são } \\
\text { discutidos. }\end{array}$ & $\begin{array}{l}\text { Tipologia: Revisão } \\
\text { da Literatura. Local: } \\
\text { Reino Unido. } \\
\text { Amostra: Não } \\
\text { informada. }\end{array}$ & $\begin{array}{l}\text { A taxa de infecção } \\
\text { diminuiu de } 9,5 \% \text { para } \\
0,5 \% \text { quando utilizada } \\
\text { uma combinação de } \\
\text { sistemas de ar limpo e } \\
\text { vestimentas oclusivas. } \\
\text { Tecido de algodão tem } \\
\text { poros de } 80 \mu \text { m e tecido } \\
\text { de fibras sintéticas } \\
\text { podem apresentar poro } \\
\text { de } 0,2 \mu \text { m, oferecendo } \\
\text { proteção muito superior. }\end{array}$ & $\begin{array}{l}\text { Nivel } 5 \text { Grau de } \\
\text { recomendação "D”, }\end{array}$ \\
\hline $\begin{array}{l}\text { MEDLINE } \\
\text { SCOPUS }\end{array}$ & $\begin{array}{l}\text { Surgeon's garb and } \\
\text { infection control: } \\
\text { What's the evidence }{ }^{26} \text {. }\end{array}$ & $\begin{array}{l}\text { Explorar as vantagens e } \\
\text { deficiências de diferentes } \\
\text { trajes cirúrgicos. }\end{array}$ & $\begin{array}{l}\text { Tipologia: Revisão } \\
\text { da literatura. Local: } \\
\text { USA. Amostra: } 8 \\
\text { artigos. Método: } \\
\text { Análise descritiva. }\end{array}$ & $\begin{array}{l}\text { Vestimentas parecem ser } \\
\text { uma das peças eficazes } \\
\text { na redução da contagem } \\
\text { bacteriana do ar. Tecido } \\
\text { de algodão tem um } \\
\text { tamanho de poro entre } \\
80 \text { e } 100 \mu \mathrm{m} \text {, o que } \\
\text { não detém as bactérias. } \\
\text { Recomenda-se o uso } \\
\text { de vestimentas que } \\
\text { sejam barreiras eficazes } \\
\text { quando molhadas. }\end{array}$ & $\begin{array}{l}\text { Nivel } 5 \text { Grau de } \\
\text { recomendação "D" }\end{array}$ \\
\hline SCOPUS & $\begin{array}{l}\text { Transfer of bacteria } \\
\text { between biomaterials } \\
\text { surfaces in the } \\
\text { operating room - An } \\
\text { experimental study }{ }^{27} \text {. }\end{array}$ & $\begin{array}{l}\text { Quantificar a } \\
\text { transferência de bactérias } \\
\text { a partir de materiais de } \\
\text { uma sala de operações } \\
\text { para outra. }\end{array}$ & $\begin{array}{l}\text { Tipologia: Estudo } \\
\text { experimental. Local: } \\
\text { Holanda. Amostra: } \\
5 \text { luvas, } 3 \text { brocas, } \\
3 \text { vestimentas } \\
\text { cirúrgicas. }\end{array}$ & $\begin{array}{l}\text { Vestidos de algodão } \\
\text { são permeáveis para as } \\
\text { bactérias (especialmente } \\
\text { quando molhados). } \\
\text { Tecido misto (poliéster e } \\
\text { algodão) libera bactérias } \\
\text { muito mais facilmente } \\
\text { do que os tecidos de } \\
\text { apenas algodão. Dos } \\
\text { tecidos descartáveis, o } \\
\text { polipropileno oferece } \\
\text { melhor proteção. }\end{array}$ & $\begin{array}{l}\text { Nivel 2B Grau de } \\
\text { recomendação "B" }\end{array}$ \\
\hline SCOPUS & $\begin{array}{l}\text { Comparison of bacteria } \\
\text { on new, disposable, } \\
\text { laundered, and } \\
\text { unlaundered hospital } \\
\text { scrubs }^{28}\end{array}$ & $\begin{array}{l}\text { Identificar e quantificar } \\
\text { os tipos de bactérias } \\
\text { heterotróficas } \\
\text { encontradas em } \\
\text { uniformes hospitalares. }\end{array}$ & $\begin{array}{l}\text { Tipologia: Estudo } \\
\text { Laboratorial. Local: } \\
\text { USA. Amostra: } 169 \\
\text { vestimentas. Método: } \\
\text { Cultura de recortes } \\
\text { das vestimentas. }\end{array}$ & $\begin{array}{l}\text { Dentre as amostras de } \\
\text { vestimentas reutilizáveis } \\
\text { ainda sujas, } 79 \% \text { foram } \\
\text { positivas para algum tipo } \\
\text { de cocos gram-positivos. } \\
\text { Não houve diferença } \\
\text { estatística nas contagens de } \\
\text { bactérias entre vestimentas } \\
\text { lavadas no hospital, as } \\
\text { sem uso e as vestimentas } \\
\text { descartáveis novas. }\end{array}$ & $\begin{array}{l}\text { Nivel 2C Grau de } \\
\text { recomendação "B", }\end{array}$ \\
\hline SCOPUS & $\begin{array}{l}\text { Behaviours and rituals } \\
\text { in the operating theatre } \\
\text { A Report from the } \\
\text { Hospital Infection } \\
\text { Society Working } \\
\text { Party* on Infection } \\
\text { Control in Operating } \\
\text { Theatres }^{29} \text {. }\end{array}$ & $\begin{array}{l}\text { Rever as evidências } \\
\text { científicas para atuais } \\
\text { práticas de controle } \\
\text { de infecção em sala } \\
\text { de cirurgia e fazer } \\
\text { recomendações. }\end{array}$ & $\begin{array}{l}\text { Tipologia: Revisão } \\
\text { da literatura. Local: } \\
\text { Irlanda. Amostra: } \\
\text { Não informada. }\end{array}$ & $\begin{array}{l}\text { A pele do profissional } \\
\text { é a fonte principal de } \\
\text { bactérias dispersas nos } \\
\text { ar. Tais bactérias passam } \\
\text { através dos interstícios } \\
\text { do tecido de algodão. } \\
\text { Houve uma redução } \\
\text { significativa nas taxas } \\
\text { de infecção no pós- } \\
\text { operatório quando uma } \\
\text { vestimenta descartável } \\
\text { era usada. }\end{array}$ & $\begin{array}{l}\text { Nivel } 5 \text { Grau de } \\
\text { recomendação "D" }\end{array}$ \\
\hline
\end{tabular}




\begin{tabular}{|c|c|c|c|c|c|}
\hline $\begin{array}{l}\text { Base de } \\
\text { Dados }\end{array}$ & Título & Objetivos & $\begin{array}{c}\text { Caracterização do } \\
\text { Estudo }\end{array}$ & Resultados & Nível de Evidência \\
\hline SCOPUS & $\begin{array}{l}\text { Occlusive Scrub } \\
\text { Suits in Operating } \\
\text { Theaters During } \\
\text { Cataract Surgery: } \\
\text { Effect on Airborne } \\
\text { Contamination }^{30} \text {. }\end{array}$ & $\begin{array}{l}\text { Estudar o efeito da } \\
\text { vestimenta oclusiva em } \\
\text { comparação à vestimenta } \\
\text { de algodão, sobre a } \\
\text { contaminação bacteriana } \\
\text { do ar durante cirurgias. }\end{array}$ & $\begin{array}{l}\text { Tipologia: Estudo } \\
\text { prospectivo de } \\
\text { intervenção. Local: } \\
\text { Noruega. Amostra: } \\
32 \text { operações. }\end{array}$ & $\begin{array}{l}\text { Vestimentas oclusivas, } \\
\text { em comparação com } \\
\text { vestimentas de algodão, } \\
\text { foram associadas com } \\
\text { uma redução superior } \\
\text { a } 50 \% \text { na carga de } \\
\text { bactérias no ar, durante } \\
\text { as operações. }\end{array}$ & $\begin{array}{l}\text { Nivel 2B Grau de } \\
\text { recomendação "B" }\end{array}$ \\
\hline $\begin{array}{l}\text { PUBMED } \\
\text { SCOPUS }\end{array}$ & $\begin{array}{l}\text { Protection Provided by } \\
\text { Clothing and Textiles } \\
\text { Against Potential } \\
\text { Hazards in the } \\
\text { Operating Theatre }^{31} \text {. }\end{array}$ & $\begin{array}{l}\text { Fornecer uma visão } \\
\text { geral da evolução nas } \\
\text { principais propriedades } \\
\text { dos tecidos e peças de } \\
\text { vestuário para uso em } \\
\text { CC. }\end{array}$ & $\begin{array}{l}\text { Tipologia: Revisão } \\
\text { da Literatura. Local: } \\
\text { Nova Zelândia. } \\
\text { Amostra: Não } \\
\text { informada. }\end{array}$ & $\begin{array}{l}\text { A eficácia de barreira de } \\
\text { tecido e não tecido de } \\
\text { vestimentas cirúrgicas } \\
\text { está relacionada ao } \\
\text { tamanho dos espaços } \\
\text { intersticiais (tamanho do } \\
\text { poro) do tecido. Espaços } \\
\text { menores correspondem a } \\
\text { propriedades superiores } \\
\text { de barreira. }\end{array}$ & $\begin{array}{l}\text { Nivel } 5 \text { Grau de } \\
\text { recomendação "D" }\end{array}$ \\
\hline $\begin{array}{l}\text { MEDLINE } \\
\text { SCOPUS }\end{array}$ & $\begin{array}{l}\text { A comparison } \\
\text { of Reusable } \\
\text { and Disposable } \\
\text { Perioperative Textiles: } \\
\text { Sustainability State-of- } \\
\text { the-Art } 2012^{32} \text {. }\end{array}$ & $\begin{array}{l}\text { Comparar } \\
\text { qualitativamente as } \\
\text { informações disponíveis } \\
\text { em relação às } \\
\text { vestimentas descartáveis } \\
\text { e reutilizáveis. }\end{array}$ & $\begin{array}{l}\text { Tipologia: Revisão } \\
\text { da literatura. Local: } \\
\text { USA. Amostra: } 6 \\
\text { artigos. }\end{array}$ & $\begin{array}{l}\text { A escolha das } \\
\text { vestimentas cirúrgicas } \\
\text { deve basear-se no tipo } \\
\text { de cirurgia. Vestimentas } \\
\text { reutilizáveis devem ser } \\
\text { rotineiramente testadas } \\
\text { para controlar o número } \\
\text { de usos, permitindo o } \\
\text { descarte no tempo de } \\
\text { vida especificado. }\end{array}$ & $\begin{array}{l}\text { Nivel } 5 \text { Grau de } \\
\text { recomendação "D" }\end{array}$ \\
\hline
\end{tabular}

algodão são mais convenientes de se usar; entretanto, possuem um tamanho de poro entre 80 e 100 micrómetros $(\mu \mathrm{m})$, o que se configura demasiado grande para conter bactérias da pele ${ }^{25,27,29,31}$. Além disso, quando as vestimentas de algodão são molhadas, organismos presentes na pele utilizam o meio líquido como transporte, penetrando mais facilmente no tecido ${ }^{25,27}$. Observa-se, também, que a capacidade de proteção após cada ciclo de uso de vestimenta reutilizável deve ser rotineiramente testada por inspeção física e testes de repelência, de forma a garantir sua eficácia. $\mathrm{O}$ número máximo de ciclos de limpeza recomendado para as vestimentas à base de poliéster, por exemplo, é de cerca de 70 ciclos. Portanto, sistemas confiáveis de registro devem controlar o número de utilizações, permitindo o recolhimento e a remoção das vestimentas fora de condições pré-determinadas de reutilização $0^{25,32}$.

Ao se realizar cultura de bactérias em placas expostas ao ar ambiente durante cirurgias, evidenciou-se uma redução na quantidade de Unidades Formadoras de Colônia (UFC) por metro cúbico $\left(\mathrm{m}^{3}\right)$ presente nas placas expostas ao ambiente, quando a equipe fez uso de sistemas de roupas feitas de poliéster. Portanto, comparadas com vestimentas feitas de mistura (algodão/poliéster), roupas feitas de poliéster ofereceram melhor proteção ${ }^{24}$. Roupas feitas de tecido de fibras sintéticas não permeáveis, como tecidos descartáveis à base de polipropileno, também oferecem proteção superior, em comparação com as roupas feitas de algodão $0^{21,30}$, podendo apresentar um poro médio de $0,2 \mu \mathrm{m}$; tais tecidos de fibras sintéticas não permeáveis são associados a uma redução superior a 50\% na carga de bactérias no ar durante as operações ${ }^{30}$ e a uma diminuição de $9,5 \%$ para $0,5 \%$ nas taxas de ISC, quando utilizados combinados a um sistema de filtragem de $a^{25}$. Entretanto, a falta de incidente documentado de contaminação bacteriana relacionada à permeabilidade têxtil sugere pouca diferença entre as vestimentas reutilizável e descartável, disponíveis atualmente ${ }^{32}$.

Com o objetivo de se intensificar a redução de dispersão de bactérias no ar, provenientes do profissional, vestimentas/ paramentações intituladas body exhaust vêm sendo testadas. A body exhaust é uma vestimenta "sem escape", ou seja, tratase de uma paramentação na qual toda a superfície da pele do corpo do profissional fica isolada, inclusive a face, porque se utiliza uma espécie de capacete com sistema próprio de exaustão. Entretanto, os achados são contraditórios, visto que estudos sugerem que a eficiência deste equipamento em promover maior proteção contra a contaminação microbiana não pôde ser comprovada ${ }^{22,26}$. Estudo ${ }^{23}$ de contagens de bactérias presentes no ar do ambiente no momento de cirurgias indica que vestimentas à base de material não tecido (polpa de poliéster) são menos eficazes do que vestimentas 
oclusivas, como a body exhaust. Contudo, identificou-se que as feridas operatórias eram igualmente contaminadas, independentemente do tipo de roupa utilizado, o que sugere que, em níveis muito baixos de contaminação do ar, a contaminação da ferida a partir do ar é irrelevante ${ }^{23}$.

Comparando-se a utilização da vestimenta body exhaust com a utilização de vestimenta convencional combinada a um sistema de unidade de fluxo de ar laminar ultrapuro, não houve diferença no número de unidades formadoras de colônias encontradas na área da operação e, além disso, a utilização de vestimenta convencional combinada a um sistema de unidade de fluxo de ar laminar ultrapuro ainda é financeiramente mais vantajosa ${ }^{22}$ e tem se mostrado eficiente, principalmente quando aliada à utilização de vestimentas livres de algodão ${ }^{24}$. Tais achados sugerem que, até o momento, não existem evidências que justifiquem a utilização das vestimentas body exhaust.

Apesar de poucos estudos testarem diretamente a capacidade de aventais e campos cirúrgicos reduzirem a infecção, afirma-se que a escolha do tipo de vestimenta cirúrgica (também denominada como aventais cirúrgicos) a ser utilizada deve basear-se no tipo de cirurgia, pois este determina o nível de proteção necessária ${ }^{32}$. A recomendação de vestimenta deve considerar condições cirúrgicas, tais como: o local da incisão cirúrgica, o tempo de duração do procedimento e a quantidade de perda sanguínea. $\mathrm{O}$ tipo de vestimenta pode variar entre vestimenta simples/ padrão (considerada avental de algodão, comumente usado), vestimenta reforçada (mais grosso que o padrão, geralmente duas camadas, não sendo necessariamente impermeáveis) e vestimenta impermeável (vestimenta plástica reforçada) ${ }^{32}$.

Assim, procedimentos cirúrgicos realizados na região do abdômen devem sempre ser realizados utilizando-se vestimenta impermeável. Nas regiões de tórax, períneo ou extremidades (braços e pernas), recomenda-se utilizar vestimenta reforçada, quando o procedimento presumir duração inferior a duas horas e perda sanguínea inferior a $100 \mathrm{~mL}$; do contrário, deve ser usada vestimenta impermeável ${ }^{32}$. Cirurgias na cabeça, no pescoço, na pele ou subcutâneas, com duração inferior a duas horas e com perda sanguínea inferior a $100 \mathrm{~mL}$, podem ser realizadas com vestimenta simples/padrão. Quando as perdas forem maiores de $100 \mathrm{~mL}$ e o procedimento ultrapassar duas horas de duração, deve ser usada vestimenta reforçada nos casos do local de incisão ser na cabeça ou no pescoço, e vestimenta impermeável nos casos de incisão em pele ou subcutânea ${ }^{32}$.

Conforme foi citado nos resultados, uma porcentagem significativa dos artigos apresentou como cenário de estudo salas de cirurgias ortopédicas, geralmente envolvendo implante de próteses. Este fato se deve pelo grande interesse deste campo de especialidade em investigar formas eficazes de diminuir ao máximo as ISC e seus riscos, visto que as infecções destes sítios trazem problemas de difícil e prolongado tratamento, além de elevar os custos, gerar um aumento de morbidade e tempo prolongado de internação, e expor o paciente a múltiplas operações, acarretando um abalo emocional considerável ${ }^{21,23}$. Todavia, com a atual e crescente atenção que os serviços de saúde estão tendo para garantir uma maior segurança para seus pacientes, tornam-se cada vez mais importantes os cuidados em relação à prevenção da IRAS, assim como a promoção de estudos que identifiquem práticas seguras relacionadas a cada etapa do cuidado.

Considerando-se o papel do Enfermeiro como elo indispensável entre as Equipes Médica e de Enfermagem, e a Comissão de Controle de Infecção Hospitalar ${ }^{10}$, compreendese a necessidade dos profissionais estarem envolvidos em atividades de qualificação, promoção e produção do conhecimento, garantindo um cuidado de qualidade baseado em evidências científicas.

\section{Considerações finais}

No ambiente de CC, as vestimentas têm como objetivo contribuir para o controle de infecções; porém, as evidências mostram que a eficiência destas vestimentas está intimamente ligada às características do material com o qual são fabricadas e às especificidades do procedimento cirúrgico em que serão utilizadas. Neste contexto, determinados materiais podem não ser eficientes para o controle de infecções, assim como também podem contribuir para a dispersão de microrganismos.

Considerando-se os dados analisados, recomenda-se: usar vestimentas cirúrgicas impermeáveis, que sejam efetivas mesmo quando molhadas; evitar utilização de vestimentas confeccionadas a partir de tecidos com poros demasiadamente grandes, e escolher o tipo de vestimenta cirúrgica a ser utilizada, baseado no tipo de cirurgia.

Contudo, devido ao baixo número de publicações atuais de forte rigor metodológico, mais estudos devem ser realizados para evidenciar mais direta e claramente o efeito desta prática nas taxas de ISC.

\section{Referências}

1. Erdmann AL, Lentz RA. Conhecimentos e práticas de cuidados mais livres de riscos de infecções hospitalares e o processo de aprendizagem contínua no trabalho em saúde. Texto Contexto - Enferm. 2004;13(esp):34-49. http://dx.doi.org/10.1590/ S0104-07072004000500004.

2. Fontana RT. As infecções hospitalares e a evolução hisórica das infecções. Rev Bras Enferm. 2006;59(5):703-6. http://dx.doi. org/10.1590/S0034-71672006000500021. PMid:17340720.

3. Oliveira R, Maruyama S. Controle de infecção hospitalar histórico e papel do estado. Rev Eletr Enf. 2008;10(3):775-83.

4. Brasil. Ministério da Saúde. Portaria no 196, de 24 de junho de 1983. Prevenção e Controle de Infecção Hospitalar. Manual de controle de infecção hospitalar. Brasília: Centro de Documentação; 1985. p. 101-5.

5. Brasil. Ministério da Saúde. Portaria no 2616, de 12 de maio de 1998. Regulamenta as ações de controle de infecção hospitalar no 
país. Diário Oficial da República Federativa do Brasil; Brasília; 15 maio 1998. Seção I.

6. Brasil. Agência Nacional de Vigilância Sanitária - ANVISA. Critérios nacionais de infecções relacionadas à assistência à saúde: sítio cirúrgico. Brasília: ANVISA; 2009 [acesso em 2013 Abr 25]. Disponível em: http://www.cve.saude.sp.gov.br/htm/ih/pdf/ manual_sitio_ciirurgico.pdf.

7. Piccoli M, Matos FGO. Diagnóstico de enfermagem de risco para infecção transoperatória fundamentado em Levine. Rev SOBECC. 2004;9(3):25-30.

8. Batista TF, Rodrigues MCS. Vigilância de infecção de sítio cirúrgico pós-alta hospitalar em hospital de ensino do Distrito Federal, Brasil: estudo descritivo retrospectivo no período 20052010. Epidemiol Serv Saúde. 2012;21(2):253-64. http://dx.doi. org/10.5123/S1679-49742012000200008.

9. Organização Mundial da Saúde - OMS. Segundo desafio global para a segurança do paciente: Manual - cirurgias seguras salvam vidas (orientações para cirurgia segura da OMS). Rio de Janeiro: Organização Pan-Americana da Saúde, Ministério da Saúde, Agência Nacional de Vigilância Sanitária; 2009. 211 p.

10. Cataneo C, Silveira CA, Simpionato E, Camargo FC, Queiroz FA, Cagnin MC. O preparo da equipe cirúrgica: aspecto relevante no controle da contaminação ambiental. Rev Lat Am Enfermagem. 2004;12(2):283-6. http://dx.doi.org/10.1590/S010411692004000200021 . PMid:15303236.

11. Brasil. Ministério do Trabalho e Emprego. Norma Regulamentadora NR-32. Segurança e saúde no trabalho em serviços de saúde. Brasília: Ministério da Saúde; 2005.

12. Conselho Regional de Enfermagem do Rio Grande do Sul COREN-RS. Decisão COREN-RS n n 061, de 02 de maio de 2006. Dispõe aos profissionais de enfermagem sobre a restrição do uso dos uniformes. Porto Alegre: COREN-RS; 2006.

13. Cardoso RS, Silva MA. A percepção dos enfermeiros acerca da comissão de infecção hospitalar: desafios e perspectivas. Texto Contexto - Enferm. 2004;13(esp):50-7. http://dx.doi.org/10.1590/ S0104-07072004000500005.

14. Azambuja EP, Pires DP, Vaz MRC. Prevenção e controle da infecção hospitalar: as interfaces com o processo de formação do trabalhador. Texto Contexto - Enferm. 2004;13(esp):79-85. http:// dx.doi.org/10.1590/S0104-07072004000500009.

15. Moura MEB, Ramos MN, Sousa CMM, Silva AO, Alves MSCF. Infecção hospitalar no olhar de enfermeiros portugueses: representações sociais. Texto Contexto - Enferm. 2008;17(4):7439. http://dx.doi.org/10.1590/S0104-07072008000400016.

16. Cooper HM. The integrative research review: a systematic approach. Newbury Park: Sage; 1989.

17. Mendes KDS, Silveira RCCP, Galvão CM. Revisão integrativa: método de pesquisa para a incorporação de evidências na saúde e na enfermagem. Texto Contexto - Enferm. 2008;17(4):758-64.

18. Souza MT, Silva MD, Carvalho R. Revisão integrativa: o que é e como fazer. Einstein. 2010;8(1):102-6.

19. Crossetti MG. Revisão integrativa de pesquisa na enfermagem o rigor científico que lhe é exigido [editorial]. Rev Gaucha Enferm. 2012;33(2):8-13. PMid:23155575.

20. Phillips B, Ball C, Sackett D, Badenoch D, Straus S, Haynes B, et al. Oxford Centre for Evidence-Based Medicine: Levels of Evidence (March 2009) [Internet]. 2009 [acesso em 2013 Jun 20]. Disponível em: http://www.cebm.net/index.aspx?o=1025.

21. Lankester BJA, Bartlett GE, Garneti N, Blom AW, Bowker KE, Bannister GC. Direct measurement of bacterial penetration through surgical gowns: a new method. J Hosp Infect. 2002;50(4):281-5. http://dx.doi.org/10.1053/jhin.2001.1154. PMid:12014901.

22. Pasquarella C, Pitzurra O, Herren T, Poletti L, Savino A. Lack of influence of body exhaust gowns on aerobic bacterial surface counts in a mixed-ventilation operating theatre. A study of 62 hip arthroplasties. J Hosp Infect. 2003;54(1):2-9. http://dx.doi. org/10.1016/S0195-6701(03)00077-X. PMid:12767840.

23. Der Tavitian J, Ong SM, Taub NA, Taylor GJS. Body-exhaust suit versus occlusive clothing. A randomised, prospective trial using air and wound bacterial counts. J Bone Joint Surg Br. 2003;85(4):490-4. http://dx.doi.org/10.1302/0301620X.85B4.13363. PMid:12793550.

24. Tammelin A, Ljungqvist B, Reinmüller B. Comparison of three distinct surgical clothing systems for protection from airborne bacteria: A prospective observational study. Patient Saf Surg. 2012;6(1):23. http://dx.doi.org/10.1186/1754-9493-6-23. PMid:23068884.

25. Sandiford NA, Skinner J. The prevention of infection in total hip arthroplasty. Orthop Trauma. 2009;23(1):8-16. http://dx.doi. org/10.1016/j.mporth.2009.01.014.

26. Eisen DB. Surgeon's garb and infection control: what's the evidence? J Am Acad Dermatol. 2011;64(5):960.e1-20. http:// dx.doi.org/10.1016/j.jaad.2010.04.037. PMid:20850894.

27. Knobben BA, van der Mei HC, van Horn JR, Busscher HJ. Transfer of bacteria between biomaterials surfaces in the operating rooman experimental study. J Biomed Mater Res A. 2007;80(4):790-9. http://dx.doi.org/10.1002/jbm.a.30978. PMid:17058211.

28. Nordstrom JM, Reynolds KA, Gerba CP. Comparison of bacteria on new, disposable, laundered, and unlaundered hospital scrubs. Am J Infect Control. 2012;40(6):539-43. http://dx.doi. org/10.1016/j.ajic.2011.07.015. PMid:22177668.

29. Woodhead K, Taylor EW, Bannister G, Chesworth T, Hoffman $\mathrm{P}$, Humphreys H. Behaviours and rituals in the operating theatre. A report from the Hospital Infection Society Working Party on Infection Control in Operating Theatres. J Hosp Infect. 2002;51(4):241-55. http://dx.doi.org/10.1053/jhin.2002.1220. PMid:12183138

30. Andersen BM, Solheim N. Occlusive scrub suits in operating theaters during cataract surgery: effect on airborne contamination. Infect Control Hosp Epidemiol. 2002;23(4):218-20. http://dx.doi. org/10.1086/502040. PMid:12002238.

31. Laing RM. Protection provided by clothing and textiles against potential hazards in the operating theatre. Int J Occup Saf Ergon. 2008;14(1):107-15. PMid:18394331.

32. Overcash M. A comparison of reusable and disposable perioperative textiles: sustainability state-of-the-art 2012. Anesth Analg. 2012;114(5):1055-66. http://dx.doi.org/10.1213/ ANE.0b013e31824d9cc3. PMid:22492184. 